\title{
Rehearsal of associations stored in long-term memory
}

\author{
RONALD E. JOHNSON \\ Purdue University, West Lafayette, Indiana 47907
}

\begin{abstract}
A 2 by 2 by 2 design in Experiment $I$ allowed comparison of rehearsers and controls assigned to one of four types of paired associate lists differing in imagery. After reaching a partial learning criterion, rehearsers engaged in covert rehearsal of associations drawn from long-term memory. Rehearsers were superior to the controls on posttreatment trials, but higher imagery was not associated with greater rehearsal gains. In Experiment II, postrehearsal success was strongly related to the relative frequencies of overt rehearsal. Rehearsals were more frequent on known associations, but rehearsal frequency also was related to new associative gain. Overall, the results support the contention that effective rehearsal may be undertaken on associations retrieved from long-term memory.
\end{abstract}

Atkinson and Shiffrin (1968) proposed a model of memory in which items in short-term storage could be entered into a rehearsal buffer for processing. Since entry into long-term memory presumably was directly related to time spent in short-term storage, an important function of rehearsal was to increase the probability of long-term remembering (Rundus, 1971; Rundus \& Atkinson, 1970). Contrary to Atkinson and Shiffrin, however, neither the processing time in short-term storage nor the frequency of overt rehearsal are necessarily related to long-term recall (Craik \& Watkins, 1973; Jacoby, 1973; Woodward, Bjork, \& Jongeward, 1973.) Short-term memories appear to be transferred into long-term storage only when the rehearser engages in semantic or associative processing (Craik \& Watkins, 1973).

Can effective rehearsal also be undertaken on the contents of long-term memory? If learners rehearse paired associates drawn from long-term memory, associative gains can occur provided that the rehearsers' memories are supplemented by access to the stimuli (Johnson, 1970). Access to responses, however, does not facilitate later performance. When rehearsers' memories are not supplemented, the outcomes have ranged from loss to marginal gain (Johnson, 1968; Rohrer, 1949; Underwood \& Keppel, 1962).

The purpose of the present experiments was to determine whether the rehearsal of long-term memories can result in associative gains. Since such rehearsal would appear dependent upon rehearsers' remembering of associative components and linkages, the variables which influence remembering presumably also would influence the effectiveness of rehearsal. Thus, higher levels of imagery were expected to result in increased availability of individual stimuli and responses for later rehearsing (Begg \& Robertson, 1973; Bower, 1972; Paivio, 1969; but see Postman \& Burns, 1973). Imagery ạlso was

Appreciation is expressed to Ellen McBride for her able assistance in data collection and analysis. Judy Anderson, Patricia Boyle, and Dennis Delph also assisted in collecting the data of Experiment 1 . expected to aid rehearsers in acquiring the correct associations between available stimuli and responses (Bower, 1972, pp. 67-68).

\section{EXPERIMENT I}

A 2 by 2 by 2 factorial design allowed comparison of rehearsers and nonrehearsers on paired associate lists composed of high or low imagery stimuli and high or low imagery responses. ${ }^{1}$ After achieving a partial learning criterion, learners received approximately $3 \mathrm{~min}$ of instructions and then received a relatively long period for rehearsal $(5 \mathrm{~min}-24 \mathrm{sec})$. Thus, rehearsers were highly dependent upon long-term memory for the material to be rehearsed.

\section{Method}

Subjects. A total of 200 subjects were randomly assigned to the eight conditions. Each condition, however, was assigned a subject before the next assignment block was begun. The subjects were undergraduates who volunteered in response to requirements of participation in experiments.

Lists. Each list contained 12 paired associates. Two nuclear lists of 12 paired associate stimuli and responses were used as the progenitors for constructing four types of lists differing in the imagery levels of the words used as stimuli and/or responses (L-L, L-H, H-L, H-H). As calibrated by Paivio, Yuille, and Madigan (1968), the imagery ratings of the stimuli and responses of one nuclear H-L list were 6.18 and 3.13; the corresponding meaningfulness ratings were 5.84 and 5.81. A socond nucleas L-H list had imagery ratings of 3.07 and 6.31 , and the corresponding meaningfulness ratings were 5.61 and 5.62 . In the construction of specific lists, the high imagory stimuli in the H-L nuclear lists were used as stimuli in each of the H-H and H-L lists, and the low imagery responses of the H-L nudlear lists were used as responses in each of the L-L and H-L lists. Similarly, the stimuli of the L-H nuclear list were used as stimuli in each of the L-L and L-H lists, and the responses of the L-H nuclear list were used as responses in each of the H-H and L-H lists.

The four list types (L-L, L-H,H-L, H-H) were each represented by five particular lists, and the paired associates in each list were displayed in four serial orders. In the assignment of serial orders and in the assignment of particular stimuli to responses, the only restriction to randomization was that sequential stimuli or responses, and stimulus-response pairings, were not allowed to have the same initial alphabetical letters. 
Table 1

Mean Performances on Pre- and Posttreatment Trials

\begin{tabular}{ccccccc} 
Group & List & $\begin{array}{c}\text { Prerehearsal } \\
\text { Trial }\end{array}$ & $\begin{array}{c}\text { Free Recall } \\
\text { of Stimuli }\end{array}$ & $\begin{array}{c}\text { Free Recall } \\
\text { of Responses }\end{array}$ & $\begin{array}{c}\text { Free Recall } \\
\text { of S-R Pairs }\end{array}$ & $\begin{array}{c}\text { Posttrial } \\
\text { Antic. }\end{array}$ \\
\hline Experiment I & & & & & & \\
Rehearsal & L-L & 8.00 & 7.36 & 8.68 & 6.60 & 8.28 \\
Control & L-L & 7.44 & 7.16 & 7.84 & 5.96 & 7.12 \\
Rehearsal & L-H & 8.00 & 8.24 & 8.84 & 7.56 & 9.20 \\
Control & L-H & 7.96 & 7.88 & 8.76 & 7.16 & 8.24 \\
Rehearsal & H-L & 7.72 & 7.80 & 8.04 & 6.72 & 9.04 \\
Control & H-L & 8.40 & 7.80 & 8.56 & 6.64 & 8.56 \\
Rehearsal & H-H & 8.28 & 9.08 & 9.60 & 8.72 & 10.44 \\
Control & H-H & 8.56 & 8.44 & 8.52 & 7.64 & 9.76 \\
Experiment II & & & & & & \\
Rehearsal & L-L & 7.70 & 7.60 & 7.90 & 6.40 & 7.30 \\
Rehearsal & H-H & 7.85 & 8.10 & 8.00 & & 9.50 \\
\hline
\end{tabular}

Procedure. The response words were pronounced rather than spelled. During the initial instructions for learning, the subjects were told that additional instructions would be given later. However, the nature of the later activity was not divulged.

A memory drum presented the lists at a 4:4-sec rate with an intertrial interval of $12 \mathrm{sec}$. After the subjects achieved a criterion of $7 / 12$, instructions were given for rehearsal or antirehearsal. The process of instructing subjects took about 3 min.

Rehearsers were told that the period of silent rehearsal offered the opportunity for review and for learning additional stimulus-response associations. In cases of uncertainty regarding associative matchings, rehearsers were advised to make a guess based upon their partial knowledges. During rehearsal, the memory drum continued to turn, but the only visible display was a sequence of printed question marks. The rehearsers were advised to recall a stimulus, and then to recall the appropriate response. Rehearsers were also encouraged to use interactive imagery in establishing associations between stimuli and responses (Bower, 1970).

Antirehearsal subjects read orally from a book of case studies. The subjects were instructed to avoid rehearsal and to change their thoughts immediately if a list word was recalled. Postexperimental inquiries revealed no evidence of illicit rehearsal.

Following $5 \mathrm{~min}$ and $24 \mathrm{sec}$ of rehearsal or reading, the subjects were instructed for a 3-min period of written free recall. The stimuli were to be written in a left-hand column, and the responses directly opposite their appropriate stimuli. If the subject could recall only one word of a pair, the word was to be listed in the appropriate column. Following free recall, an overt anticipation trial was given in which each stimulus was presented for $4 \mathrm{sec}$, and the subjects attempted to recall the appropriate response during the 4-sec interval.

\section{Results}

Mean performances on the pre- and posttreatment trials are shown in the upper portion of Table 1. Separate analyses of variance indicated that the rehearsal and antirehearsal (control) groups were equivalent on all pretreatment performances [all $F s(1 / 192)=<1$, ps $>.05]$. Performances on the final pretreatment trial were higher for groups having high imagery stimuli $[F(1 / 192)=6.84, p<.01]$ and for groups having high imagery responses $[F(1 / 192)=4.32, p<.05]$.
Since the pretreatment superiorities on the high imagery lists were equivalent for rehearsal and antirehearsal groups $[F(1 / 192)=<1, p>.05]$, tests of the experimental hypotheses are not invalidated. To assist interpretation, however, analyses of covariance (ANOCOVA) were calculated with multiple covariates of trials to criterion, number of correct responses to criterion, and correct responses on the final pretreatment trial. Covariance analyses are reported if the multiple regression coefficient significantly exceeded zero $(p=<.05)$; otherwise, ANOVAs are reported.

Posttreatment free recall. The rehearsal groups were not superior to the controls in the free recall of stimuli [ANOVA $F(1 / 192)=1.52, p>.05$ ] or responses [ANOCOVA $F(1 / 189)=2.58, p>.05]$, but the rehearsers had more correct stimulus-response pairings in free recall [ANOCOVA $F(1 / 189)=5.08, p<.05$ ]. Nonsignificant interactions between rehearsal-antirehearsal and stimulus imagery in the free recall of stimuli [ANOVA $\mathrm{F}(1 / 192)=<1, \mathrm{p}>.05$ ], responses [ANOCOVA $F(1 / 189)=<1, p>.05$ ], and stimulus-response pairings [ANOCOVA $F(1 / 189)=<1$, $p>.05]$ indicate that the superior recall of stimulus-response pairs by the rehearsers was not due to differential advantages on lists with high imagery stimuli. Similarly, the rehearsal-antirehearsal variable showed no significant interactions with response imagery either in the free recall of stimuli [ANOVA $F(1 / 192)=<1$, $p>.05$ ], responses [ANOCOVA $F(1 / 189)=1.12$, $\mathrm{p}>.05$ ], or stimulus-response pairs [ANOCOVA $F(1 / 189)=<1, p>.05]$.

Postanticipation trial. Rehearsers were superior to the controls in the posttreatment anticipation trial [ANOCOVA $F(1 / 189)=14.79, p<.001]$, and a repeated-measures ANOVA of performances from the final criterion trial to the postanticipation trial showed greater gains for the rehearsal than the control groups 
$[F(1 / 192)=14.15, p<.001]$. Comparable to free recall, there were no significant interactions between response imagery and the rehearsal variable $[F(1 / 192)=\langle 1, p>.05]$, nor between stimulus imagery and the rehearsal variable $[F(1 / 192)=3.51$, $\mathrm{p}<.05]$; the apparent closeness to significance reflects relatively better performances by the controls on lists with high imagery stimuli. The nonsignificance of the triple interactions between rehearsal-control, trials, and stimulus or response imagery $[\mathrm{Fs}(1 / 192)=<1$, ps $>.05]$ was further evidence that the rehearsal groups gained no differential advantage from high imagery.

\section{EXPERIMENT II}

Atkinson and Shiffrin's (1968) theoretical views received strong empirical support from the finding that the free recalls of individual words were directly related to the relative frequencies of overt rehearsal (Rundus, 1971; Rundus \& Atkinson, 1970). Procedurally, leamers were presented a word for $5 \mathrm{sec}$, and then allowed $5 \mathrm{sec}$ of oral rehearsal. Rehearsers were free to rehearse any word, but the bulk of the rehearsals were repetitions of the immediately preceding word. Thus, learners rehearsed content drawn primarily from short-term memory.

In Experiment II of the present study, two rehearsal groups were required to rehearse overtly. The purpose of the experiment was to see if the relation between overt rehearsals and postrehearsal performances also could be extended to the rehearsal of associations retrieved from long-term memory.

\section{Methods}

Procedure. Unless otherwise indicated, the procedures in Experiment II were identical to Experiment I. Forty subjects were alternately assigned to two rehearsal groups receiving either a $\mathrm{H}-\mathrm{H}$ or a $\mathrm{L}-\mathrm{L}$ list. Rehearsers were advised not to be concerned about the quality of their verbal output, and to vocalize whatever came to mind. During a pilot study, however, some rehearsers became silent. Since silence could signify either an absence of rehearsal or covert rehearsal, a renewed vocalization was encouraged by an experimenter's comment such as "Please rehearse out loud" or "I'm sorry, I can't hear you." Any period of silence longer than $20-25 \mathrm{sec}$ prompted an experimenter comment.

Analysis, Oral rehearsals were tape recorded and then transcribed. A rehearser's response of saying a stimulus and then its response was scored as a stimulus rehearsal, a response rehearsal, and also a stimulus-response rehearsal. The temporal lag between a stimulus and its response was not a determinant of scoring, and the lag exceeded $5 \mathrm{sec}$ on only three occasions. If an intrusion occurred between a stimulus and its response, credit was not allowed for a stimulus-response rehearsal. An occurrence of a response followed by its stimulus also was not credited as a correct stimulus-response rehearsal. Incorrect pairings were scored as separate instances of stimulus or response rehearsals.

Analyses of variance showed the two rehearsal groups did not differ in mean stimulus rehearsals $\left[M_{H}=41.4, R=19-119\right.$, vs. $M_{L}=39.6, \quad R=11-69, \quad F(1 / 38)=\langle 1, \quad p>.05]$, response rehearsals $\left[\mathrm{M}_{\mathrm{H}}=37.9, \mathrm{R}=19-122\right.$, vs. $\mathrm{M}_{\mathrm{L}}=34.3, \mathrm{R}=16-63$, $F(1 / 38)=\langle 1, p\rangle .05]$, or correct stimulus-response rehearsals $\left[\mathrm{M}_{\mathrm{H}}=30.5, \mathrm{R}=15-105\right.$, vs. $\mathrm{M}_{\mathrm{L}}=24.1, \mathrm{R}=5-61, \mathrm{~F}(1 / 38)=$ $1.42, p>.05]$. As computed across all subjects, stimulus rehearsals correlated .88 with response rehearsals, and .90 with stimulus-response rehearsals. Response rehearsals correlated .93 with stimulus-response rehearsals.

For each of the three types of rehearsal, a between-subjects' rehearsal variable was formed by categorizing subjects into four groups according to total rehearsals. A within-subjects variable, a measure of relative rehearsal on each associate, was determined by ordering the 12 paired associates of each subject according to

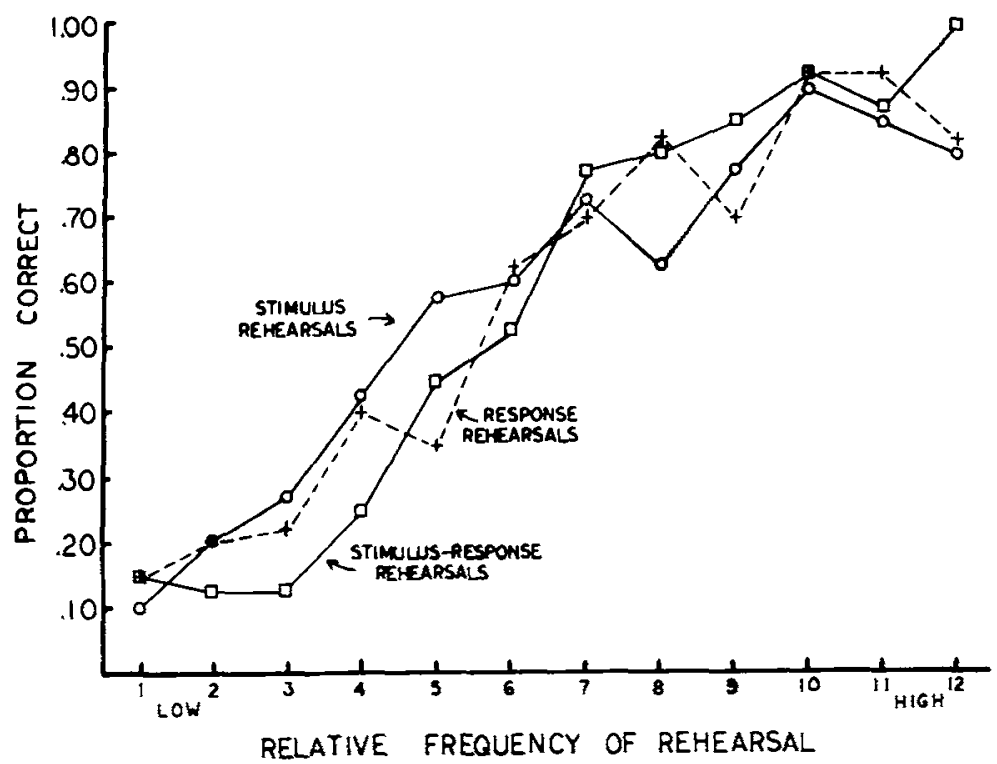

Figure 1. Free recall of $\mathbf{S}-\mathbf{R}$ pairs as related to relative frequencies of rehearsal. 
relative frequencies of rehearsal. The basic design thus was a 2 by 4 by 12 , with two types of lists, four levels of absolute rehearsal, and 12 levels of relative rehearsal. For each type of rehearsal, analyses of variance were performed on each of the performances in free recall and on the postrehearsal anticipation trial.

\section{Results and Discussion}

The two rehearsal groups showed equivalent performances on the final trial prior to rehearsal [ANOVA $F(1 / 32)=<1, p>.05$ ]. Mean performances are shown in the lower portion of Table 1. Analyses of the free recall data showed nonsignificant differences in recalling stimuli $[\mathrm{F}(1 / 32)=1.20, \mathrm{p}>.05]$ and responses $[F(1 / 32)=<1, p>.05]$; the difference in correct associative pairings was marginally shy of significance at the .05 level $[F(1 / 32)=4.10]$. The rehearsers with high imagery lists were superior on the postanticipation trial $[F(1 / 32)=16.39, p<.001]$. Significant pre- to postgains were evidenced by the high imagery rehearsers $[F(1 / 19)=28.31, p<.001]$, but not by the low imagery rehearsers $[F(1 / 19)=\langle 1, p>.05]$.

For each of the three types of rehearsal, the relative frequencies of rehearsals on the particular paired associates were strongly related to each of the four postrehearsal performances on the respective paired associates [all ANOVA $F s(11 / 352)=>5.83$, all ps $<.001]$. Since the types of rehearsal were highly intercorrelated, a detailing of each analysis would be redundant. Therefore, in Figure 1, an illustrative set of data is given, showing the probabilities of correctly recalling the stimulus-response pairs in free recall, as related to the relative frequencies of the three types of rehearsal.

The absolute number of stimulus rehearsals, and also the absolute number of stimulus-response rehearsals, were directly related to each of the overall performances in free recall [all ANOVA $F_{S}(3 / 32)=>9.50$, all ps $<.001]$. Learners showing more response rehearsals performed somewhat better in the free recall of responses $[F(3 / 32)=3.40, p<.05]$ and associative pairs $[F(3 / 32)=2.90, \quad p<.05]$, but not stimuli $[F(3 / 32)=1.97, p>.05]$. Postrehearsal anticipation performances were not related to the absolute number of rehearsals of any type $[\mathrm{Fs}(3 / 32)=<1.74$, ps $>.05]$, except that the mean number of stimulus-response rehearsals was related to the number of correctly anticipated responses $[\mathrm{F}(3 / 32)=3.01, \mathrm{p}<.05]$.

Despite the strengths of the relationships between rehearsal and postrehearsal performances, the illustrative data in Figure 1, and the data of Rundus and Atkinson(1970) and Rundus (1971) are not sufficient to establish causality. An alternative explanation might be that the frequencies of oral rehearsal simply index associative strengths at the time of beginning rehearsal.

In assessments of this possibility, analyses of variance showed that the relative frequency of stimulus rehearsa' was not related to correct anticipations on the $k$ pretreatment trial, $[F(11 / 352)=1.80, p>.05]$, but correctness on the last pretreatment trial was related to the relative frequency of response rehearsal $[F(11 / 352)=2.80, \quad \mathrm{p}<.01]$ and stimulus-response rehearsal $[F(11 / 352)=3.13, p<.001]$. Thus, the strong relationship between rehearsal frequency and postrehearsal performance occurs, in part, because rehearsers are more likely to rehearse associations that are already known.

What function, then, does rehearsal serve? A warmup hypothesis might suggest that rehearsal aids performance through maintenance of a set to recall rather than through direct associative gain (e.g., Irion, 1949). Another hypothesis might be that rehearsal exerts a direct strengthening effect on known associations, or else lessens the probability of forgetting. As predicted by either explanation, the probability that correct responses on the pretreatment trial would remain correct on the postanticipation trial was directly related to the relative frequencies of stimulus rehearsal [ANOVA $F(11 / 352)=2.25, \quad p<.05] ;$ response rehearsal [ANOVA $F(11 / 352)=3.01, p<.001] ;$ and stimulus-response rehearsal [ANOVA $\mathrm{F}(11 / 352)=4.17$, $p<.001]$.

The warmup hypothesis, however, would predict that incorrect responses also would be maintained from the pre- to postanticipation trials. In contrast to the warmup hypothesis, analyses of variance showed that the persistence of an incorrect response was inversely related to the relative frequency of rehearsing stimuli $[F(11 / 352)=4.11, p<.001] ;$ responses $[F(11 / 352)=6.36, p<.001]$; and stimulus-response pairings $[F(11 / 352)=7.01, p<.001]$.

Even more damaging to the hypothesis that rehearsal serves only a maintenance function, analyses of variance showed that associative gain from the pre- to postanticipation trials was directly related to the relative frequency of stimulus rehearsal $[F(11 / 352)=3.14$, $p<.001]$, and stimulus-response rehearsal $[F(11 / 352)=1.97, p<.05]$. A significant interaction between lists and the frequency of stimulus-response rehearsal $[F(11 / 352)=2.55, p<.01]$ reflected the relatively greater gains on the high imagery list for higher levels of relative frequency of rehearsal. In accord with the finding that stimulus rehearsal is more critical for associative gain than is response rehearsal (Johnson, 1970), the relative frequency of response rehearsal was not related to associative gain $[F(11 / 352)=1.31$, $p>$.05].

\section{GENERAL DISCUSSION}

Rehearsal resulted in associative gain even when rehearsers were dependent upon long-term memory for access to the content to be rehearsed. The superiority of rehearsers was evident both in the free recall of 
stimulus-response pairs and in postrehearsal anticipation performance. In accomplishing this associative gain, learners apparently were able to recycle long-term memories back into the rehearsal mechanism for additional processing.

Contrary to expectations, the effectiveness of rehearsal was not additionally enhanced by higher levels of imagery. Since the low and high imagery words were learned to the same performance criterion prior to rehearsal, it is probable that the two types of words were not appreciably different in availability at the beginning of rehearsal. Rehearsers presumably can rehearse only that which is available for rehearsal, and it is perhaps not surprising that the rehearsal gains were equivalent for the two types of material.

The results of Experiment II provide additional evidence of the generality of the relationship between oral rehearsals and later postrehearsal performances. In contrast with the procedures used in earlier experiments (Rundus, 1971; Rundus \& Atkinson, 1970), oral rehearsals were undertaken on the contents of long-term memory, and the rehearsal period was relatively long and unstructured. Instead of a serial list, the subjects learned paired associates, and were tested both on free recall and anticipation performances. In all comparisons, the relative frequencies of the various rehearsals were directly related to each of the measures of postrehearsal competence. The strength of the relationship between rehearsal and later recall was due, in part, to the tendency of learners to rehearse the associations which were already known. Additional analyses, however, gave evidence that the higher the relative frequency of rehearsal, the greater was the probability that a correct item would stay correct, the less likely was the probability that an incorrect item would stay incorrect, and the greater was the probability that there would be associative gain.

At both the theoretical and empirical levels, the distinction between short-term memory and long-term memory is fast fading (e.g., Wickelgren, 1973), and the present research adds to the blurring of the distinction. Provided that researchers engage in associative encodings, memories in the short-term store can be entered into a long-term store. In turn, memories in the long-term store can be returned to the short-term store for additional rehearsal, and the consequence of additional rehearsal can be new associative gains stored in long-term memory. The distinguishability of the two storages thus becomes blurred as a direct function of the ease with which subjects can use rehearsal strategies in interchanging the contents of the two registers.

\section{REFERENCES}

Atkinson, R. C., \& Shiffrin, R. M. Human memory: A proposed system and its control processes. In $K$. W. Spence \& J. T. Spence (Eds.), The psychology of learning and motivation: Advances in research and theory. Vol, 2. New York: Academic Press, 1968.

Begg, I., \& Robertson, R. Imagery and long-term retention. Journal of Verbal Learning and Verbal Behavior, 1973, 12 , 689-700.

Bower, G. H. Imagery as a relational organizex in associative learning. Journal of Verbal Learning and Verbal Behavior, $1970,9,529-533$.

Bower, G. H. Mental imagery and associative learning. In $L$. W. Gregg (Ed.), Cognition in learning and memory, New York: Wiley, 1972 .

Craik, F. I. M. \& Watkins, M. J. The role of rehearsal in short-term memory. Journal of Verbal Leaming and Verbal Behavior, 1973, 12, 599-607.

Irion, A. L. Retention and warming-up effects in paired-associate learning. Journal of Experimental Psychology, 1949, 39. $669-675$.

Jacoby, L. L. Encoding processes, rehearsal, and recall requirements. Journal of Verbal Learning and Verbal Behavior, 1973, 12, 302-310.

Johnson, R. E. Rehearsal effectiveness as a function of similarity of rehearsal activities to a paired-associate task. Journal of Verbal Leaming and Verbal Behavior, 1968, 7, 439-445.

Johnson, R. E. Differential availability of associative components in rehearsal. Journal of Experimental Psychology, $1970,85,356-360$.

Paivio, A. Mental imagery in associative learning and memory. Psychological Review, 1969, 76, 241-263.

Paivio, A., Yuille, J. C., \& Madigan, S. Concreteness, imagery, and meaningfulness values for 925 nouns. Journal of Experimental Psychology Monograph Supplement, 1968, 76 (1, Pt. 2).

Postman, L. \& Burns, S. Experimental analysis of coding processes. Memory \& Cognition, 1973, 4, 503-507.

Rohrer, J. H. Factors influencing the occurrence of reminiscence: Attempted formal rehearsal during the interpolated period. Journal of Experimental Psychology. $1949,39.484-491$.

Rundus, D. Analysis of rebearsal processes in free recall. Journal of Experimental Psychology, 1971, 89, 63-77.

Rundus, D.. \& Atkinson, R. C. Rehearsal processes in tree recall: A procedure for direct observation. Journal of Experimental Psychology, 1970, 9, 99-105.

Underwood, B. J., \& Keppel, G. An evaluation of two problems of method in the study of retention. American Journal of Psychology, 1962, 75, 1-17.

Wickelgren, W. A. The lons and short of memory. Psychological Bulletin, 1973, 80, 425-438.

Woodwand, A. E., Jr., Bjork, R. A., \&ongeward, R. H., Jr. Recall and recognition as a function of primary rehearsal Journal of Verbal Leaming and Verbal Behavior, 1973, 12 , 608-617.

\section{NOTE}

1. The results of Experiment 1 were presented in a paper delivered at the May 1973 meeting of the Midwestem Psychological Association, Chicago.

(Received for publication March 26, 1974; revision accepted November 30,1974 .) 